\title{
Logo-autobiography and its effectiveness on depressed Korean immigrant women: A replication study
}

\author{
Kunsook S. Bernstein ${ }^{1}$, Sunhee $\mathrm{Cho}^{2}$, Soyeon $\mathrm{Cho}^{3}$, Soonhee $\mathrm{Roh}^{4}$ \\ 1. School of Nursing, Hunter College, the City University of New York, USA. 2. Department of Nursing, Mokpo National \\ University, South Korea. 3. Human Services Department, NYC College of Technology, the City University of New York, USA. \\ 4. School of Health Sciences, University of South Dakota, SD, USA
}

Correspondence: Sunhee Cho. Address: Dept. of Nursing, Mokpo National University, 1666 Yeongsan-ro, Cheonggyemyeon, Muan-gun, Jeollanam-do 534-729, South Korea. Telephone: 82-61-450-2676. E-mail: scho@mokpo.ac.kr.

Received: July 5, 2012

Accepted: October 17, 2012

DOI : $10.5430 /$ jnep.v3n6p51

URL: http://dx.doi.org/10.5430/jnep.v3n6p51

Online Published: December 27, 2012

\section{Abstract}

Objective: This study aimed to examine the longevity of Logo-Autobiography (LA)'s effects and to identify whether different providers and different types of LA intervention have diverse impact on the outcomes for Korean immigrant women with depression.

Methods: A pre-experimental research was conducted with pre-, post-, and 4-week follow-up tests using the CES-D depressive symptoms and Purpose in Life scales. LA included a structured weekly session for 6 weeks in either individual or group setting, and autobiography writing with predesigned topics for each session. A total of 47 subjects participated in this study. Repeated measures of ANOVA were conducted to investigate if there were differences between the experimental and control groups.

Results: All hypotheses were supported that the experimental group showed 1) significantly lower scores on depressive symptoms, 2) significantly higher scores on purpose in life, and 3) no differences of depressive symptoms and meaning of life scores between medication and non-medication groups, group vs. individual interventions, and among three different providers in the post-test and the 4-week follow-up test.

Conclusions: LA may be considered as another alternative therapeutic intervention in treating Korean-American immigrant women who suffer from depression and lost meaning in life. Further studies are needed with a larger sample size using rigorous randomized designs to validate the effectiveness of the LA.

\section{Key words}

Depression, Korean American immigrant women, Logo-autobiography, Meaning of life

\section{I ntroduction}

Logo-Autobiography (LA) is an effective form of existential psychotherapy developed in South Korea for women married to husbands who abuse alcohol ${ }^{[1,2]}$. To expand its applicability and to examine the sustainability of its effects, the researchers replicated the LA intervention for immigrant Korean women experiencing depressive symptoms in the United 
States ${ }^{[3]}$. In that study ${ }^{[3]}$, the results confirmed that LA was effective in reducing depressive symptoms and improving sense of meaning of life among Korean immigrant women at the post-test and the 4-week follow-up.

The present study aimed to evaluate its effectiveness as a therapeutic modality in helping depressed individuals by replicating the prior LA study ${ }^{[3]}$. In addition, another purpose of this study was to examine whether different intervention providers and different types of intervention (individual therapy vs. group therapy) influence treatment outcomes.

LA is grounded in the philosophy of existentialism and Victor Frankl's logotherapy ${ }^{[4,5]}$. A guided autobiography is an intervention for education, counseling, and psychotherapy that is grounded in reminiscence and life review ${ }^{[6]}$. LA was modified by integrating conventional logotherapy and guided autobiography intervention based on three concepts: the freedom of will, the will to meaning, and the meaning of life ${ }^{[4]}$. Depression during acculturation has been classified as existential or anomic depression ${ }^{[7]}$, which encompasses the notion that life is meaningless when people experience a life crisis ${ }^{[5,8]}$. This concept of existential depression may apply to immigrants who often experience stress and anxiety during the transition of moving from one culture to another, which may so pronounced as to be personally considered as a life crises ${ }^{[9]}$.

Socioeconomic deprivation along with cultural confusion among immigrants during the acculturation process can negatively affect an individual's perception of the meaning of life. Immigrants may experience acculturative stress as well as a sense of loss of purpose in life, which may lead to the development of psychiatric disorders including depression ${ }^{[10,11]}$.

Depression was listed as one of the most serious mental health problems experienced by immigrant women ${ }^{[12]}$; but it was often undiagnosed and therefore not treated due to language barriers and limited access to services ${ }^{[13]}$. Korean immigrant women were not exception to this category ${ }^{[13,14]}$. Another study reported that Korean immigrants in the U.S. displayed higher depression scores than the general population ${ }^{[15]}$.

Despite this, studies on the treatment of depression for Korean immigrants in the U.S. are limited. Moreover, the lack of cultural sensitivity on the part of mental health professionals and access to appropriate therapeutic interventions have been barriers for Korean Americans seeking mental health services for psychological problems in the U.S. Since current conventional psychotherapy is often described as "talk therapy", it can be viewed by immigrants, especially Asian immigrants, as ineffective, costly, intrusive, and time-consuming ${ }^{[16]}$. Alternative therapy designed to help immigrants who are going through a transitional life crises is needed. The Korean word, 'Han', represents a syndrome characterized by regret or resentment, which is culturally a unique emotion for Koreans ${ }^{[17]}$. This is especially true for Korean women with 'Han' who have a tendency to internalize their feelings, and have fewer emotional outlets and social supports. In addition, Asian women tend to disclose more personal information and share more thoughts and feelings than Asian men, and focus on relationships and family when they talk about their lives ${ }^{[18]}$. Considering that the LA is designed to find one's meaning of life as an immigrant and express one's feelings such as 'Han' through journaling, the LA might have potential to be a culturally sensitive and appropriate therapy for depressed Korean immigrant women in the U.S.

\section{Methods}

\subsection{Research design}

A non-randomized quasi-experimental design was used with pre-test, post-test, and follow-up test. An experimental group and a control group were designed, and then sub-groups such as medication or non-medication were added in each group by adopting quota sampling method in order to control the confounding effects of antidepressants on the dependent variables. Finally, sub-groups were as follows: 1) Experimental group with anti-depressant (Ex-Med), 2) Experimental group without anti-depressant (Ex-NoMed), 3) Control group with anti-depressant (Con-Med), and 4) Control group without anti-depressant (Con-NoMed). Three different providers who were bilingual Korean and English scholars with 
mental health care background (1 original LA developer, 1 psychiatric mental health nurse practitioner, and 1 psychiatric social worker) provided the LA intervention. The instructional manual of the LA designed by the original LA developer ${ }^{[1]}$ was used to train other LA providers which provided a clear instruction of the LA implementation, and so the differences in the outcomes could diminish among the three LA providers in this study. The effect of intervention was measured at three phases; pre-test for baseline information; post-test immediately after the LA; and 4-week after the end of the intervention.

\subsection{Sample}

Sampling criteria were Korean immigrant women who were 21 years and older, scored 16 and higher on the Center for Epidemiologic Studies Depression scale (CES-D), were able to speak, read, and write the Korean language, and resided in New York City (NYC). The sample size of study was calculated based on the Cohen ${ }^{[19]}$ and Hulley \& Cummings ${ }^{[20]}$ formula. By calculating the effect size $(d=.50, \alpha=.10$, and power $=.80)$, the minimum number of study participants is 36 . In this study, sixty five participants were recruited and 47 were included in the study. Of the 18 excluded subjects, 10 subjects ( 2 from the experimental group and 8 from the control group) did not complete the study due to lack of time and/or loss of interest, and 8 did not meet the sample criterion of depressive symptom score $(<16)$. Eleven of the 23 subjects taking antidepressants were assigned to the experimental group and the remaining 12 to control group; 10 of 24 subjects not taking antidepressants were assigned to the experimental group and the remaining 14 were assigned to the control group (see Figure 1). The 21 subjects in the experimental group, 8 were assigned in group and 13 in individual settings.

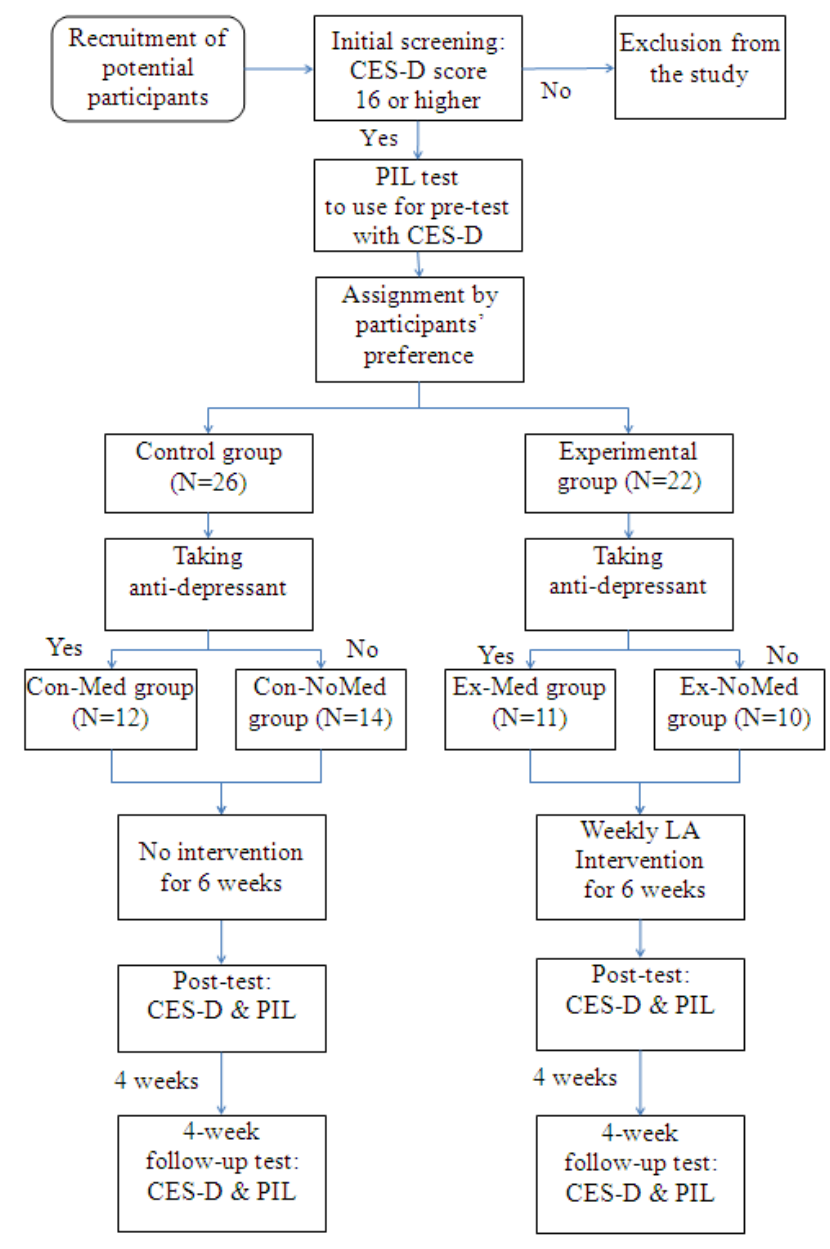

Figure 1. Algorithm of the research procedure 


\subsection{I nstruments}

The Korean version of CES-D ${ }^{[21]}$ was used to measure depressive symptoms in the pre-test, post-test, and 1-month follow-up test. The original version of the CES-D is one of the most widely-used self-report instruments for depression screening in the general population ${ }^{[22]}$. The CES-D is a 20 -item measure and each item is rated on a 4-point scale from 0 to 3. Total scores range from 0 (no depressive symptoms) to 60 (most severe depression), and a score of 16 or higher identifies subjects with depressive symptoms. It was found to have high internal consistency (Cronbach's $\alpha=.89$ ) and adequate test-retest reliability ${ }^{[23]}$. Reliability, validity, and factor structure were similar across a wide variety of demographic characteristics in the general population samples tested ${ }^{[24]}$.

The Korean version of Purpose-In-Life (PIL) ${ }^{[25]}$ was used to measure the participant's sense of meaning in life. It was designed by Crumbaugh and Maholick ${ }^{[26]}$ to operationalize Frankl's ideas of an existential vacuum by measuring an individual's sense of meaning in life. The PIL is a 20 -item scale that has been shown to have good reliability of alpha coefficients from .86 to $.97^{[27]}$. Each item is rated on a 7-point scale from 1 to 7, and total scores range from 20 (low purpose) to 140 (high purpose). Individuals who score 112 and higher on the PIL scale are considered to have a sense of purpose in life by holding beliefs that their lives are meaningful and carrying certain goals and aims toward life in general. Individuals who score 92 and lower are considered to lack a sense of purpose in life, have few goals, lack a sense of direction in life, and do have a meaningful outlook on life ${ }^{[28]}$. Park and Lee ${ }^{[25]}$ tested the cultural and content validity of the PIL test in Korea after translating it into Korean, and found a Cronbach's $\alpha$ of 0.91 .

\subsection{Data collection}

After approval by the university and the hospitals' institutional review boards, data were collected between January 2010 and November 2010. The researcher who developed the LA ${ }^{[1]}$ trained two additional researchers how to conduct the LA program for the experimental group using the scripted LA program manual ${ }^{[29]}$. All three LA providers were doctoral level mental health clinicians with at least 10 years of clinical experience. Each LA provider recruited their own subjects by contacting a local community hospital, two mental health clinics, and two Korean community organizations in NYC after obtaining permissions from each organization. Once permission was obtained, the researchers visited the agency and explained the purpose of the study to the head of each organization. The agency staff identified potential participants and informed them about the study.

After the completion of the CES-D as an initial screening, a PIL test was given; these two assessments were used for baseline data (pre-test) (see Figure 1). Participants in the experimental group received six, 60-minute LA sessions once a week for 6 weeks. The intervention was provided in private rooms in the clinics or Korean community center. For the control group, the researchers conducted a pre-test, post-test, and follow-up test in the same way without providing the LA. Among the experimental group, 8 participants chose to attend the group settings and the remainder of the 16 subjects preferred to be seen individually.

\subsection{I ntervention}

The 6-week, once-weekly 60 minute session aims to explore a specific theme for each session guided by the designated LA provider sequentially: (week 1) self-introduction, orientation and production of a chronology, (week 2) exploring meaningful relationships in one's life before migration, (week 3) exploring meaningful relationships in one's life after migration, (week 4) exploring one's crises and self-attitude toward crises before migration, (week 5) exploring one's crises and self-attitude toward crises after migration, and (week 6) reading one's autobiography.

Each session consisted of four stages: (1) warm-up for 5 minutes, (2) writing one's autobiography on the designated topic for 25 minutes, (3) presenting a written autobiography on the topic, and, for 25 minutes, discussing it with the LA provider to find meanings, and (4) sharing one's feelings and summarizing the experiences of the LA for 5 minutes. At the end of the fifth session, handwritten autobiographies from all five sessions were collected, and then the LA provider typed 
collected materials into a word processor and made a bound book for each participant. In the last session, the LA provider returned the bound autobiography book to each participant to read and share feelings.

\subsection{Data analyses}

Data analyses were completed using SPSSWIN 19.0. The analysis for this study proceeded in two steps. First, to explore characteristics of sample and to test homogeneity among control and treatment groups, $t$-test (for interval variables), and chi-square test (categorical variables) were used. Second, Repeated Measures of ANOVA were conducted to investigate the difference of dependent variables between the experimental and the control groups, and among various subgroups. A number of reasons supported the selection of Repeated Measures of ANOVA for main hypothesis testing. First, two groups were compared (treatment vs. control group). Second, two or more factors were compared within the treatment group - 1) medication vs. non-medication, 2) group vs. individual, and 3) 3 different LA intervention providers.

\section{Results}

\subsection{Sample characteristics and homogeneity tests}

Table 1. Homogeneity Tests on Demographic Characteristics and Outcome Variables at Baseline

\begin{tabular}{|c|c|c|c|}
\hline Variables & $\begin{array}{l}\text { Control Group } \\
(\mathrm{N}=\mathbf{2 6})\end{array}$ & $\begin{array}{l}\text { Intervention Group } \\
(\mathrm{N}=\mathbf{2 1})\end{array}$ & \\
\hline & Mean (SD) & Mean (SD) & $t(p)$ \\
\hline Age (years) & $51.42(14.17)$ & $56.81(11.31)$ & $1.75(.16)$ \\
\hline \multirow[t]{2}{*}{$\begin{array}{l}\text { Duration of Stay } \\
\text { (years) }\end{array}$} & $16.88(10.19)$ & $21.33(11.47)$ & $.059(.16)$ \\
\hline & Frequency (\%) & Frequency (\%) & $\chi^{2}(p)$ \\
\hline Education & & & $7.1(.21)$ \\
\hline Middle & $1(3.8)$ & $0(0)$ & \\
\hline High & $7(26.9)$ & $6(28.6)$ & \\
\hline Junior college & $2(7.7)$ & $3(14.3)$ & \\
\hline 4 yr college & $11(42.3)$ & $4(19)$ & \\
\hline Graduate & $0(0)$ & $3(14.3)$ & \\
\hline Religion & & & $3.02(.55)$ \\
\hline None & $2(7.7)$ & $3(14.3)$ & \\
\hline Buddhism & $5(19.2)$ & $2(9.5)$ & \\
\hline Catholic & $6(23.1)$ & $3(14.3)$ & \\
\hline Others & $1(3.8)$ & $0(0)$ & \\
\hline Marital Status & & & $4.71(.31)$ \\
\hline Never married & $8(30.8)$ & $4(19)$ & \\
\hline Divorced & $4(15.4)$ & $3(14.3)$ & \\
\hline Married & $9(34.6)$ & $10(47.6)$ & \\
\hline Separated & $2(7.7)$ & $4(19)$ & \\
\hline Widowed & $3(11.5)$ & $0(0)$ & \\
\hline Income & & & $10.94(.36)$ \\
\hline 0-9999 & $6(23.1)$ & $9(42.9)$ & \\
\hline $10-30 \mathrm{k}$ & $7(26.9)$ & $6(28.5)$ & \\
\hline $30-50 \mathrm{k}$ & $8(30.8)$ & $3(14.3)$ & \\
\hline $50-70 \mathrm{k}$ & $2(7.7)$ & $1(4.8)$ & \\
\hline $70-90 \mathrm{k}$ & $2(7.6)$ & $2(7.6)$ & \\
\hline Depression & $25.11(10.28)$ & $27.0(11.01)$ & $-.61(.55)$ \\
\hline Purpose in Life & $76.30(24.77)$ & $84.04(29.32)$ & $-.98(.33)$ \\
\hline
\end{tabular}

The socio-demographic characteristics of subjects in the control group and experimental group were compared and were summarized in Table 1. There were no significant differences in the socio-demographic characteristics between two groups. The mean age in the control group $(\mathrm{n}=26)$ was 51.42 years $(\mathrm{SD}=14.17)$ and 56.81 years $(\mathrm{SD}=11.31)$ for the 
experimental group $(\mathrm{n}=21)$. The mean duration of residence in the U.S. for the control group was 16.88 years $(\mathrm{SD}=10.19)$ and $21.33(\mathrm{SD}=11.47)$ for the experimental group. In both two groups, approximately a half of subjects were currently married (control group: 34.6\%, experimental group: 47.6\%) and college educated or higher (control group: 50.0\%, experimental group: 47.6\%). Most respondents (control group: 69.3\%, experimental group: 76.2\%) were either Protestant or Catholic. Table 1 also shows depressive symptoms and purpose in life scores at baseline in both the control and experimental groups. There were no significant differences in the baseline score of depressive symptoms, $t(45)=-.61$, $p=.55$, and meaning of life, $t(45)=-.98, p=.33$, between the control and experimental groups.

\subsection{Findings of hypotheses testing and dependent variables}

Table 2 showed the repeated measure of ANOVA results for the first hypothesis. After receiving the LA intervention, the participants in the experimental group showed a decrease on depressive symptom scores, which lasted to the 1-month follow up, $\mathrm{F}(1,2)=4.86, p=.002$. Similar to the first hypothesis, second hypothesis was supported as well. Participants in the experimental group scored higher on perceived meaning in life at the post-test and 1 month-follow up, $F(1,2)=10.93$, $p=.002$, than those in the control group.

Table 2. Repeated Measures of ANOVA: Effects of Intervention Measured at Three Time Points

\begin{tabular}{|c|c|c|c|c|c|}
\hline \multirow[b]{2}{*}{ Variables } & \multirow[b]{2}{*}{ Groups } & Pre-test & Post-Test & Follow-Up & \multirow[b]{2}{*}{$F(p)$} \\
\hline & & $\begin{array}{l}\text { Mean } \\
\text { (SD) }\end{array}$ & $\begin{array}{l}\text { Mean } \\
\text { (SD) }\end{array}$ & $\begin{array}{l}\text { Mean } \\
\text { (SD) }\end{array}$ & \\
\hline Depression & Control & $\begin{array}{l}25.11 \\
(2.08)\end{array}$ & $\begin{array}{l}26.31 \\
(2.22)\end{array}$ & $\begin{array}{l}24.88 \\
(1.98)\end{array}$ & \multirow[t]{2}{*}{$\begin{array}{l}4.86^{* * *} \\
(.00)\end{array}$} \\
\hline \multirow{3}{*}{ Purpose in Life } & Intervention & $\begin{array}{l}27.00 \\
(2.32)\end{array}$ & $\begin{array}{l}16.43 \\
(2.47)\end{array}$ & $\begin{array}{l}14.48 \\
(2.20)\end{array}$ & \\
\hline & Control & $\begin{array}{l}76.31 \\
(5.28)\end{array}$ & $\begin{array}{l}73.28 \\
(4.30)\end{array}$ & $\begin{array}{l}79.62 \\
(3.96)\end{array}$ & \multirow[t]{2}{*}{$\begin{array}{l}10.93^{* *} \\
(.01)\end{array}$} \\
\hline & Intervention & $\begin{array}{l}84.05 \\
(5.87)\end{array}$ & $\begin{array}{l}98.24 \\
(4.79)\end{array}$ & $\begin{array}{l}104.19 \\
(4.41)\end{array}$ & \\
\hline
\end{tabular}

${ }^{*} p<.05, * * p<.01, * * * p<.001$

When the effectiveness of LA between medication and non-medication groups was examined, the results found that both groups (groups on medication and non-medication) did show effectiveness of LA $(F(1,2)=5.28)$ and between group difference was not significant $(\mathrm{F}(1,2)=2.04, p=.16)$.

In testing whether there was an interaction between medication treatment and the LA intervention on depressive symptoms, the findings suggest there was no significant interaction found between medication and LA intervention effecting on depressive symptoms over time (Table $3 ; \mathrm{F}(1,2)=.08, p=.78$ ). When impact of medication and LA therapy on perceived meaning in life was examined, results showed that interaction between medication and LA therapy on perceived meaning in life was not significant, $(\mathrm{F}(1,2)=.43, p=.51)$.

Table 3. Interaction Between Medication and LA Therapy on Outcome Variables

\begin{tabular}{|c|c|c|c|c|}
\hline & Type III & df & $F$ & $p$ \\
\hline Medication by group ${ }^{\dagger}$ on Depression & 21.56 & 1 & .08 & .78 \\
\hline Medication by group on Purpose of Life & 442.12 & 1 & .43 & .51 \\
\hline
\end{tabular}

$\dagger$ Group indicates control group vs. LA therapy intervention group

Next set of analyses was performed only with those who received LA therapy to find out whether 1) types of therapy (group vs. individual), and 2) types of therapy provider make difference in the effect of LA therapy on depressive symptoms and perceived meaning in life. The results showed that there is no main effect in the types of therapy on 
depressive symptoms (see Figure 2, top left; $\mathrm{F}(1,2)=1.83, p=.19$ ), and on perceived meaning in life (see Figure 2, top right; $\mathrm{F}(1,2)=2.60, p=.12$ ). The main effect of different provider on the depressive symptoms and perceived meaning in life were examined next. The results suggested that provider did not have main effect on depressive symptoms (see Figure 2, bottom left; $\mathrm{F}(2,4)=1.19, p=.33$ ). However, the main effect of provider was found on the perceived meaning in life (see Figure 2, bottom right; $\mathrm{F}(2,4)=3.72, p=.04)$.
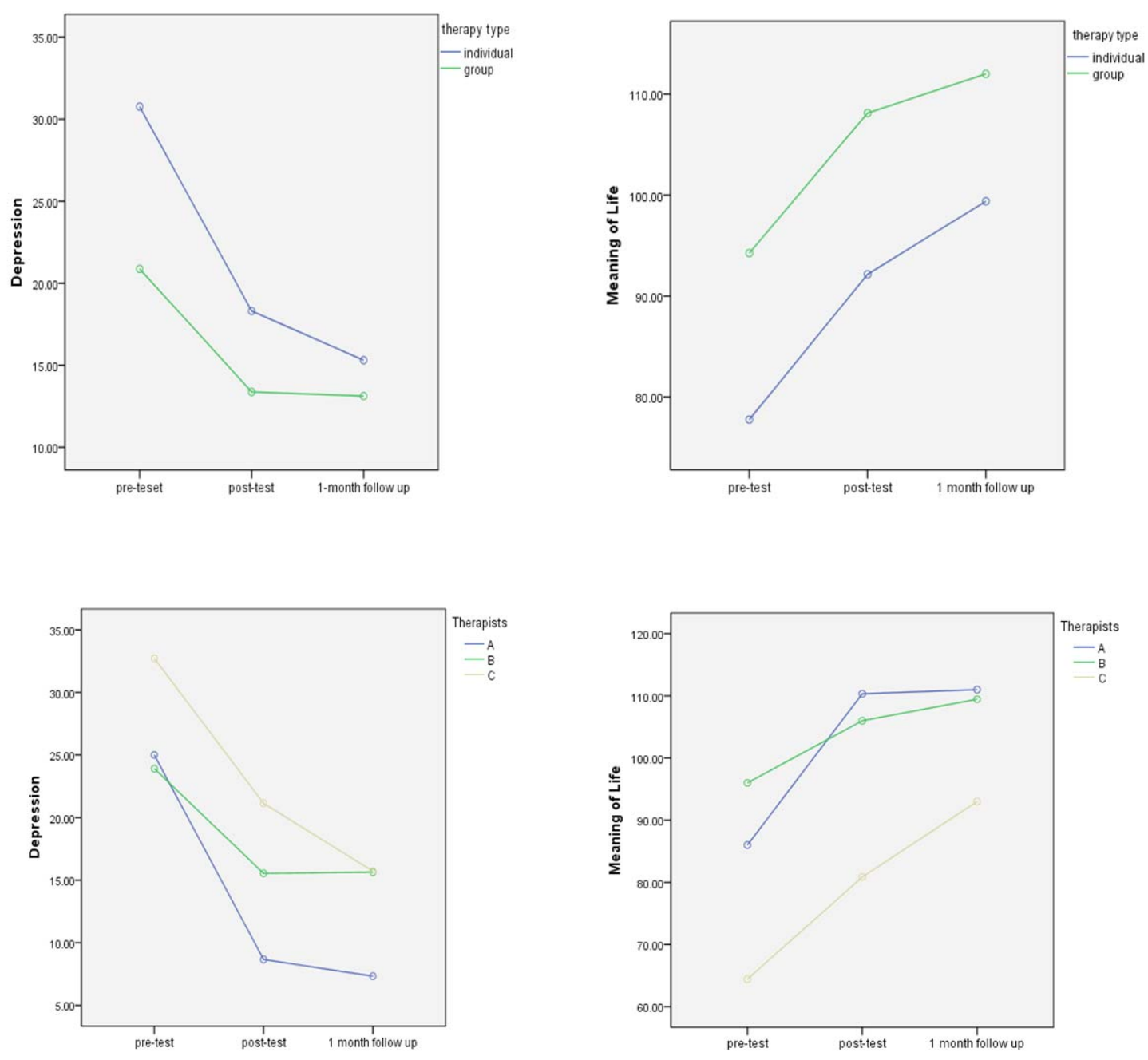

Figure 2. Interaction plots

\section{Discussion}

This paper reports a replication study of the LA as a therapeutic intervention for treating Korean American immigrant women suffering from depression. The outcome of this study was consistent with the outcome of the previous study ${ }^{[3]}$ that the LA was effective in lowering depressive symptoms and increasing the Purpose in Life score.

The findings of this study indicated that the participants in the experimental group reported lower scores of depressive symptoms and higher scores on perceived meaning in life than those in the control group in the post-test and the 1 month-follow up test. There are various non-conventional therapies similar to the LA intervention that use creative ways to retrieve one's memories to enhance his/her purpose and find meaning in life. The present finding is consistent with the 
findings of other studies which utilized searching for the meaning in one's life as an intervention method with depressed elderly ${ }^{[30]}$, reviewing one's life method and measuring its effectiveness on self-esteem and life satisfaction ${ }^{[31]}$, and expressive writing and its impact on stress and physical symptoms ${ }^{[32]}$. Overall, the outcomes of these studies including the LA support that a well-structured intervention program designed to review one's life stories and search for meaning in life can be effective as interventional method for individuals with chronic emotional distress. The LA is one of few interventional modalities designed to search one's meaning of life and find purpose in life as an immigrant that it may have potential to be a culturally appropriate and receptive therapeutic intervention for depressed Korean American immigrant women. Additionally, the LA as an evidence-based intervention can be replicated in future studies with other sub-ethnic Asian American women suffering from depression.

Overall, the findings of this study was consistent with that of the original study of LA and searching for meaning in life and promoting mental health in the Korean wives of alcoholics ${ }^{[1]}$. Existential psychotherapy has been reported as effective for people suffering from chronic depression with existential despair ${ }^{[35]}$. A study of individuals suffering with terminal illness such as cancer can also benefit from finding meaning in life through therapeutic interventions such as logotherapy ${ }^{[33]}$ and meaning-centered group psychotherapy ${ }^{[34]}$.

According to Frank ${ }^{[4]}$, human beings try to determine the cause of their suffering, and finding the meaning and purpose is the fundamental desire which may relieve their suffering. Several researchers tried to apply this principle to people suffering from terminal cancer ${ }^{[33,34]}$, trauma ${ }^{[11]}$, and depression ${ }^{[27,35]}$ and found that Frankl's fundamental was effective to reduce the suffering by understanding the meaning of suffering. Logo-autobiography based on this fundamental was applied to depressed Korean immigrant women for symptom reduction and it was effective to relieve their suffering such as depressive symptoms and meaninglessness. We may assume that they discovered the meanings of suffering and then changed their 'attitudinal values' ${ }^{[4]}$ which refer to the stand we take toward fate because attitude is the ability to face suffering with courage when confronted with unchangeable events ${ }^{[37]}$.

Another finding of this study was that there was no difference in the effectiveness of the LA between medication and non-medication groups, group vs. individual sessions, and the outcomes among the three LA intervention providers. Whether or not participants were medicated, the LA intervention did not differ in the outcome of depressive symptoms and purpose in life. This finding, however, is not consistent with the findings from the previous study. Unlike the current study, the previous study reported that the LA was more effective in improving depressive symptoms and meanings in life for the participants who were not on medication compared to those who were on medication ${ }^{[3]}$. Advancement of psychopharmacology has brought medication as an intricate part of depression treatment along with psychotherapy. A study by Arnow and Constantino ${ }^{[36]}$ reported that a combination of medication and psychotherapy demonstrated significant superiority over medication or psychotherapy alone in chronic major depression ${ }^{[34]}$. The outcome of the present study, which was inconsistent from the previous study, needs to be further explored.

There were also no statistically significant differences in the outcomes of depression and purpose in life scores between the group versus the individual intervention sessions. This is consistent with a study of patient education, which separated the type of education to group or individual sessions, and reported that there was no difference in the outcome of the patient education between the group and the individual sessions ${ }^{[35]}$. Lastly, there were no significant differences in the outcomes of the effectiveness of the LA among the three LA intervention providers. This hypothesis was intended to measure whether the styles of different therapists superseded the impact of LA on the study outcome. We concluded that the instructional manual of the LA provided a sound and clear instruction for the LA providers before the LA implementation and confirmed the manual's reliability regardless the styles of different therapists in this study.

Another noteworthy finding was the lasting effectiveness of the LA in the 1-month follow-up. This result was consistent with the original study as well as the study of Chiang et al. ${ }^{[29]}$, which had a similar design measuring 1-month follow-up evaluation and its lasting effects. Also, there were minor changes in research design between the previous study and the 
present study: the sample size was increased from 40 in the previous study to 47 in the present study, and the number of the LA intervention providers was increased from one in the previous study to three in the present study.

Overall, this replication study strengthens the effectiveness of the LA as a therapeutic modality for Korean immigrant women. The present findings could provide for mental health providers as another alternative therapeutic intervention in treating Korean-American immigrant women who suffer from depression and lost meaning in life.

\section{Limitations}

This replication study was conducted by the same researchers who conducted the original study, which may not be ideal for a replication study. Also, there is limited literature related to this topic to support its relevance and discrepancy, other than the previous study. Similar to the previous study, this study is a non-randomized study with a small sample size. Another methodological limitation is the potential influence of the method of assigning the participants in the control group and the experimental group. Since this study used a non-randomized convenient sampling, the group assignment of the participants was not controlled in terms of the participants' status of depression and purpose in life between the two groups.

\section{Conclusions}

The study supports that the LA can be an effective therapeutic intervention in treating Korean American immigrant women who suffer from depression and lost meaning in life. However, further studies are needed with a larger sample size, using rigorous randomized research designs, and clear inclusion and exclusion criteria to validate the effectiveness of the LA before it can be conclusively claiming to be a robust therapeutic interventional modality for Korean American immigrant women. Additionally, this study can be replicated with other sub-ethnic Asian American women suffering from depression.

\section{Acknowledgements and Funding}

This project was supported by Goolsby 2009 NP Research Grant from American Academy of Nurse Practitioner Foundation, USA, and Research Foundation of City University of New York.

\section{References}

[1] Cho S. Effects of logo-autobiography program on meaning in life and mental health in the wives of alcoholics. Asian Nurs Res. 2008; 2: 129-139. http://dx.doi.org/10.1016/S1976-1317(08)60036-5

[2] Cho S. Meaning of life in wives of alcoholics: autobiographical method. J Korean Acad Nurs. 2008; 38: 758-767. PMid:19114765 http://dx.doi.org/10.4040/jkan.2008.38.5.758

[3] Cho S, Bernstein KS, Roh S, Chen D. Logo-Autobiography and its effectiveness on depressed Korean immigrant women. J Transcult Nurs, in press. PMid:22802301

[4] Frankl VE. The will to meaning. New York: World Publishing Company, 1969.

[5] Frankl VE. Man's search for meaning: An introduction to Logotherapy. New York: Washington Square Press, 1963. Earlier title 1959: From Death-Camp to Existentialism. Originally published in 1946 as Ein Psycholog erlebt das Konzentrationslager.

[6] Thornton JE. The guided autobiography method: A learning experience. Int J Aging Hum Dev. 2008; 66: $155-173$. PMid:18453181 http://dx.doi.org/10.2190/AG.66.2.d

[7] Harper K, Lantz J. Cross-cultural practice: Social work with diverse populations. Chicago: Lyceum Books, 1996.

[8] Yalom ID. Existential psychotherapy. New York: Basic Books, 1980.

[9] Berger R, Weiss T. Immigration and posttraumatic growth-A missing link. J Immigr Refug Serv. 2002; 1: 21-39. http://dx.doi.org/10.1300/J191v01n02_02

[10] Mui AC, Kang S. Acculturation stress and depression among Asian immigrant elders. Soc Work. 2006; 51: $243-255$. PMid:17076122 http://dx.doi.org/10.1093/sw/51.3.243 
[11] Noh S, Kaspar V. Perceived discrimination and depression: Moderating effects of coping acculturation and ethnic support. Am J Public Health. 2003; 93: 232-238. PMid:12554575 http://dx.doi.org/10.2105/AJPH.93.2.232

[12] Ezeobele I, Malecha A, Landrum P, Symes L. Depression and Nigerian-born immigrant women in the United States: A phenomenological study. J Psychiatr Ment Health Nurs. 2010; 17: 193-201. PMid:20465767 http://dx.doi.org/10.1111/j.1365-2850.2009.01519.x

[13] Mui AC. Stress, coping and depression among elderly Korean immigrants. J Hum Behav Soc Environ. 2001; 33: $281-299$.

[14] McCracken M, Olsen M, Chen Jr. MS, Jemal A, Thun M, Cokkinides V. et al. Cancer incidence, mortality, and associated risk factors among Asian Americans of Chinese, Filipino, Vietnamese, Korean, and Japanese ethnicities. CA Cancer J Clin. 2007; 57: 190-205. PMid:17626117 http://dx.doi.org/10.3322/canjclin.57.4.190

[15] Bernstein KS, Park S, Shin J, Cho S, Park Y. Acculturation discrimination and depressive symptoms among Korean immigrants in New York City. Community Ment Health J. 2011; 47: 24-34. PMid:19888652 http://dx.doi.org/10.1007/s10597-009-9261-0

[16] Kung WW. Cultural and practical barriers to seeking mental health treatment for Chinese Americans. J Community Psychol. 2004; 32: 27-43. http://dx.doi.org/10.1002/jcop.10077

[17] Pang KYC. Symptoms of depression in elderly Korean immigrants: Narration and the healing process. Cult Med Psychiatry. 1998; 22: 93-122. PMid:9657060 http://dx.doi.org/10.1023/A:1005389321714

[18] Haight B, Nomura T, Nomura A. Life review as an Alzheimer's intervention: Results of an American Japanese project. Dimensions. 2000; 7: 4-8.

[19] Cohen J. Statistical power analysis for the behavioral sciences. Hillsdale,NJ:Lawrence Erlbaum Associates, 1969.

[20] Hulley SB, Cummings SR. Designing clinical research - An epidemiologic approach. PA: Lippincott Williams \& Wilkins, 1988.

[21] Chon KK, Choi SC, Yang BC. Integrated adaptation of CES-D in Korea. Korean J Health Psychol. 2001; 6: 59-76.

[22] Radloff LS. The CES-D Scale: A self-report depression scale for research in the general population. Appl Psychol Meas. 1977; 1: 385-401. http://dx.doi.org/10.1177/014662167700100306

[23] Wong YI. Measurement properties of the Center for Epidemiologic studies-Depression Scale in a homeless population. Psychol Assess. 2000; 12: 69-76. PMid:10752365 http://dx.doi.org/10.1037/1040-3590.12.1.69

[24] Kazarian SS. Validation of the Armenian center for epidemiological studies depression scale (CES-D) among ethnic Armenians in Lebanon. Int J Soc Psychiatry. 2009; 55: 442-448. PMid:19700484 http://dx.doi.org/10.1177/0020764008100548

[25] Park GJ, Lee KH. A structural model for depression in middle-aged women. Korean J Women Health Nurs. 2002; 8: 69-84.

[26] Crumbaugh JC, Maholick LT. An experimental study in existentialism: The psychometric approach to Frankl's concept of noegenic neurosis. J Clin Psychol. 1964; 20: 200-207. http://dx.doi.org/10.1002/1097-4679(196404)20:2<200::AID-JCLP2270200203>3.0.CO;2-U

[27] Schulenberg S.E. Empirical research and logotherapy. Psychol Rep. 2003; 93: 307-319. PMid:14563068

[28] Ryff CD, Keyes CLM. The structure of psychological well-being revisited. J Pers Soc Psychol. 1995; 69: 719-727. PMid:7473027 http://dx.doi.org/10.1037/0022-3514.69.4.719

[29] Cho S. Development and application of a Logotherapeutic Autobiography Program for wives of alcoholics. PhD thesis. Seoul National University, College of Nursing, Seoul, South Korea, 2007.

[30] Bohlmeijer E, Valenkamp M, Westerhof G, Smit F, Cuijpers P. Creative reminiscence as an early intervention for depression: Results of a pilot project. Aging Ment Health. 2005; 9: 302-304. PMid:16019285 http://dx.doi.org/10.1080/13607860500089567

[31] Chiang K, Lu R, Chu H, Chang Y, Chou K. Evaluation of the effect of a life review group program on self-esteem and life satisfaction in the elderly. Int J Geriatr Psychiatry. 2008; 23: 7-10. PMid:17477451 http://dx.doi.org/10.1002/gps. 1824

[32] Creswell JD, Lam S, Stanton AL, Taylor SE, Bower JE, Sherman DK. Does self-affirmation cognitive processing or discovery of meaning explain cancer-related health benefits of expressive writing? Pers Soc Psychol Bull. 2007; 33: 238-250. PMid:17259584 http://dx.doi.org/10.1177/0146167206294412

[33] Brat PT. Logotherapy in the care of the terminally ill. J Relig Gerontol. 2001; 11: 103-117. http://dx.doi.org/10.1300/J078v11n03_09

[34] Breibart W, Rosenfeld B, Gibson C, Pessin H, Poppito S, Nelson C et al. Meaning-centered group psychotherapy for patients with advanced cancer: A pilot randomized controlled trial. Psychooncology. 2010; 19: 21-28. PMid:19274623 http://dx.doi.org/10.1002/pon.1556

[35] Ghaemi SN. Feeling and time: The phenomenology of mood disorders depressive realism and existential psychotherapy. Schizophr Bull. 2007; 33: 122-130. PMid:17122410 http://dx.doi.org/10.1093/schbul/sbl061

[36] Arnow BA, Constantino MJ. Effectiveness of psychotherapy and combination treatment for chronic depression. J Clin Psychol. 2003; 59: 893-905. PMid:12858430 http://dx.doi.org/10.1002/jclp.10181

[37] Marshall M, Marshall E. Logotherapy revisited: Review of the tenets of Viktor E. Frankl's logotherapy. Ottawa: CreateSpace Independent Publishing Platform, 2012. 